\title{
Voces de invasión e iniciativas disruptivas en Buenos Aires en los primeros años de la década de 1820
}

\section{Voices of invasion and disruptive initiatives in Buenos Aires, in the early years of the 1820 s}

\author{
Fabián Herrero \\ CONICET, Instituto Ravignani \\ Universidad de Buenos Aires \\ Universidad Autónoma de Entre Ríos \\ Argentina
}

Recibido: $16 / 02 / 2018$

Aceptado: 22/04/2018

Resumen. "La feliz experiencia de Buenos Aires", en contraste con el crítico año veinte, fue un periodo de reformas económicas, sociales, institucionales, entre otras, que habría ocurrido en un clima de relativa paz, ausencia de facciones y resolución de viejos conflictos. Este trabajo intenta matizar esta imagen. A modo de hipótesis se sostiene aquí que la oleada reformista que afecta a autoridades (Cabildo), territorios (expansión frontera y política con los indios), sujetos e instituciones (reformas del clero, militar, imprenta) no se dio en un clima de relativa paz, ausencia de facciones y resolución de viejos conflictos, por el contrario, ocurrió en una escena abierta y dinámica atravesada por distintos movimientos de redes de grupos y fracciones políticas, con vocación de poder (por vía armada o electoral) y espacios de conflicto y de tensión, y con problemas históricos que no parecen haberse cerrado al finalizar la crisis de 1820. Las fuentes utilizadas remiten a fondos de Gobierno, Causas judiciales y Policía, la amplia prensa del período, las sesiones de la Junta de Representantes y el Cabildo, los informes y memorias de testigos.

Palabras clave Buenos Aires-Guerra-revolución-contrarrevolución-política

Abstract. "The happy experience of Buenos Aires", in contrast to the critical twenties, was a period of economic, social and institutional reforms which would 
have occurred in a climate of relative peace, absence of factions and resolution of old conflicts. This paper tries to tint this image. As a hypothesis, it is believed that the reformist wave that affects authorities (Cabildo), territories (border and political expansion with the Indians), subjects and institutions (reforms of the clergy, military, printing) did not occur in a climate of relative peace, absence of factions and resolution of old conflicts, on the contrary, occurred in an open and dynamic scene traversed by different movements of networks of political groups and fractions, with a vocation of power (by armed or electoral), spaces of conflict and historical problems that do not seem to have closed at the end of the crisis of 1820. The sources used refer to funds from the Government, Causes and Police, the broad press of the period, the sessions of the Board of Representatives and the Cabildo, the reports and reports of witnesses.

Keywords: Buenos Aires-war-revolution-counterrevolution-politics

\section{Introducción}

Al concluir el crítico año de 1820, según las perspectivas generales más conocidas, se clausuran de alguna manera viejos problemas irresueltos y, al mismo tiempo, se abre la posibilidad para comenzar a diagramar nuevas políticas. En clave de resolución de conflictos, 1820 es visto como un punto de inflexión en la historia de Buenos Aires: la facción federal es derrotada en la revolución de octubre, abriéndose, de esta manera, una flamante etapa con escasa circulación de fuerzas opositoras, por lo menos hasta 1824; el largo conflicto que sostiene la provincia, durante la década de 1810, con sus pares del litoral, tuvo, sin sombra de duda, uno de sus momentos más agudos con la invasión y la ocupación de algunas zonas del territorio por parte de sus principales caudillos. Esta problemática situación habría concluido, finalmente, con el acuerdo celebrado entre Estanislao López y Juan Manuel de Rosas. También es conocido que, en clave reformista, se presentan una serie numerosa de iniciativas. Entre las más destacadas, pueden mencionarse la expansión de la frontera, donde los sectores productivos pudieron ampliar su horizonte de producción y de ganancias; la extinción de los Cabildos de la provincia (ese antiguo vestigio de la Colonia) y la emergencia de una Sala de Representantes que ofrecía un espacio de representación a la ciudad capital y a todos los pueblos 
rurales. Al mismo tiempo, se sanciona una verdadera catarata de leyes: una nueva ley electoral que, como ha mostrado inteligentemente Marcela Ternavasio, permite un "voto amplio", directo y una apertura de la "frontera política" de la campaña, pero también otras como, por ejemplo, una ley de imprenta que reemplaza a la de 1811 o la relativa al clero regular. Además, se crea la Universidad y se editan más órganos periodísticos, como no había sucedido antes ${ }^{1} \ldots$ en fin, un cúmulo sustantivo de medidas que, junto a la resolución de viejos conflictos, proyectaron la imagen que algunos de sus propios protagonistas definieron como la "feliz experiencia de Buenos Aires". Sus marcas sobresalientes han sido resumidas en tres puntos: relativa paz, resolución de conflictos y escasa presencia de fracciones de oposición.

¿Es posible que una oleada de reformas que afecta, de un modo u otro, a autoridades, territorios, sujetos, no haya recreado una escena mucho más conflictiva que lo señalado habitualmente? ¿Es posible que activas e intensas fracciones políticas que, con distinta fuerza y suerte, han circulado en el dominio público porteño durante toda la década de 1810 queden con escasos o relativo signo de actividad en todo este período? ¿Es posible, en fin, que las tensiones y conflictos

\footnotetext{
1 Sobre las reformas rivadavianas, los trabajos más clásicos y todavía muy útiles, HALPERIN DONGHI, Tulio, Revolución y Guerra. Formación de una elite dirigente en la Argentina criolla, Buenos Aires, Siglo XXI, 1972; BAGÚ, Sergio, El plan económico del grupo rivadaviano (18111827), Rosario, UNL, 1966. Una perspectiva más actual y que profundiza sobre algunas de ellas, TERNAVASIO, Marcela, "Las reformas rivadavianas en Buenos Aires y el Congreso General Constituyente (1820-1827), en Noemí GOLDMAN (dir. de tomo), Nueva Historia Argentina, Buenos Aires, Sudamericana, 1998, tomo III. BARRAL, María E., "Un salvavidas de plomo. Los curas rurales y la reforma eclesiástica de 1822", Prohistoria, Rosario, julio/diciembre, 2010. AYROLO, Valentina, El abrazo reformador. Las reformas eclesiásticas en tiempos de construcción estatal Córdoba y Cuyo en el concierto iberoamericano (1813-1840), Rosario, Prohistoria, 2017. Sobre la resolución de conflictos, entre muchos otros menciono el más clásico, HALPERIN DONGHI, Tulio, Revolución..., ob. cit. Un balance e interpretación muy inteligente sobre los movimientos de protesta, FRADKIN, Raúl, "Cultura política y acción colectiva en Buenos Aires (1806-1829): un ejercicio de explicación”, en Raúl FRADKIN (ed.), ¿Y el pueblo dónde está? Contribuciones para una historia popular de la revolución de independencia en el Río de la Plata, Buenos Aires, Prometeo Libros, 2008. Sobre la cuestión de los miliares y la guerra, RABINOVICH, Alejandro, "Milicias, ejércitos y guerras", en M. TERNAVASIO (Dir.), De la organización provincial a la federalización de Buenos Aires (1821-1889), Tomo 3 de la Historia de la provincia de Buenos Aires, Buenos Aires, UNIPE-Edhasa, 2013. HERRERO, Fabián, "Conflictos políticos, económicos, militares...Buenos Aires y la guerra con la República de Entre Ríos”, Pasado Abierto, ${ }^{\circ}{ }^{1}$, Mar del Plata, enero-junio, 2015.
} 
Voces de invasión e iniciativas disruptivas...

abiertos con las provincias del litoral se hayan clausurado con el acuerdo entre el primer mandatario santafesino y uno de los máximos militares bonaerenses?

Este trabajo se inserta dentro de las investigaciones que hace un tiempo, desde dimensiones históricas diversas, vienen marcando tramas conflictivas durante este período. De este modo, se trata de hacer ver un cuadro un poco más complejo y dinámico, en donde la oleada de reformas y los intentos de instaurar un nuevo orden de paz se desarrollan, de modo casi paralelo, a momentos de tensiones, de conflictos e incluso de iniciativas de poder alternativo. En este preciso sentido, por ejemplo, se presentan estudios que han puesto el centro de su interés en algunas tensiones percibidas en la lucha electoral, en el dominio de la prensa de tono opositor, los conflictos en torno a los jueces letrados o a los curas rurales, la movilización de la población en la contienda bélica con la República de Entre Ríos. ${ }^{2}$

Para tratar de dar algún tipo de respuesta a los interrogantes señalados, divido este artículo en dos partes. En primer lugar, interesa examinar el impacto en Buenos Aires de la guerra con la República de Entre Ríos, que transcurre entre finales del año 1820 y 1821. Este suceso, desde este ángulo interpretativo, no resultó de interés por parte de la historiografía; los escasos estudios específicos solo examinan el territorio del litoral pero no la de sede porteña. En este punto retomo algunos aspectos de un trabajo anterior. En segundo lugar, importa analizar los movimientos de carácter rupturista que se presentan en el año 1822. Las llamadas

\footnotetext{
2 Menciono solo algunas que aluden a problemáticas diferentes. TERNAVASIO, Marcela, La Revolución del voto, Política y elecciones en Buenos Aires 1810-1852, Buenos Aires, Siglo XXI, 2002, pp.113-125. DI MEGLIO, Gabriel, iViva el bajo pueblo! La plebe urbana de Buenos Aires y la política entre la revolución de mayo y el rosismo, Buenos Aires, Prometeo, 2007. Y "La participación política popular en la provincia de Buenos Aires, 1820-1890", en Raúl FRADKIN y G. DI MEGLIO (comp.), Hacer política. La participación para una historia popular de la revolución de independencia en el Río de la Plata, Buenos Aires, Prometeo Libros, 2013. CALVO, Nancy, "Voces en pugna, prensa política y religión en los orígenes de la República Argentina", Hispania Sacra, vol. 61, n 122, oct., 2008. FRADKIN, Raúl, “Cultura política..., ob. cit. Y “¿Misión imposible? La fugaz experiencia de los jueces letrados de la primera instancia en la campaña de Buenos Aires (1822-1824)", en D. BARRIERA (comp.), Justicias y fronteras. Estudios sobre la justicia en el Río de la Plata (siglos XVII-XIX), Murcia, Editum, 2009. BARRAL, María E., "Un salvavidas...”, ob. cit. HERRERO, Fabián, "Conflictos políticos...ob. cit, y "Algunas líneas de impugnación a los 'filósofos' reformistas. Francisco Castañeda en el contexto de la reforma del clero en Buenos Aires en los inicios de 1820", Andes, $\mathrm{n}^{\circ}$ 26, Universidad Nacional de Salta, 2015. GALIMBERTI, Vicente, "La unanimidad en debate. Los procesos electorales en la campaña de Buenos Aires entre 1815 y 1828 ", en Boletín del Instituto de Historia Argentina y Americana "Dr. E. Ravignani”, n 37, 2012.
} 
"conspiraciones de Tagle" no fueron analizadas en su conjunto, sí es posible mencionar el muy sugestivo estudio de Di Meglio sobre la que estalla en marzo de 1823, donde pone el foco de atención en el eje política y plebe. Las investigaciones del período solo mencionan la de 1822 pero no hacen una indagación de ella, como tampoco se nombran los hechos disruptivos provocados y vinculados con ella por parte del fraile Francisco Castañeda o los que ocurren en la campaña.

\section{La guerra. Buenos Aires frente a la República de Entre Ríos}

Hacia fines de 1820, Francisco Ramírez, Jefe Supremo de la República de Entre Ríos, inicia un movimiento armado contra Buenos Aires, Santa Fe y Córdoba. Visto este acontecimiento desde sede porteña, el plan tiene varios planos: primero, "la invasión de la provincia", seguidamente, un cambio del elenco gobernante a manos de los federales locales que lo acompañan en esta empresa (entre los que figuran Carlos Alvear y Manuel Sarratea) ${ }^{3}$ y por último, organizar un poder federal, en cuanto su intención es que la "facción federal" produzca "división en el país" y "su ruina", al otorgar "soberanía a ciudades y pueblos sin peso" y al permitir el "saqueo de Buenos Aires"..4 Bien podríamos afirmar que la guerra, en primer lugar, es percibida como una guerra ideológica o de poder, ya que tiene el efecto de introducir serias consecuencias tanto en el orden estatal como en la seguridad de la comunidad.

\section{1. ¿Qué hace el Gobierno de Buenos Aires?}

Dispone de todo un arsenal de medidas tanto económicas como de defensa. En marzo, se ordena que "deben tomar las armas", concretamente, "todo habitante

\footnotetext{
3 Esta versión oficial de Buenos Aires, "Agresión de Ramírez contra la provincia de Buenos Aires", Gaceta de Buenos Aires, Buenos Aires, 30 de mayo de 1821. Véase del mismo periódico, "Circular", 28 de enero de 1821; "Noticias interiores", 30 de mayo de 1821; y con el mismo título, 16 y 23 de mayo de 1821. Una versión similar en IRIARTE, Tomás, Memorias. Rivadavia, Monroe y la guerra argentino-brasileña, Buenos Aires, Ediciones Argentinas, 1945, p. 12.

4 Sobre la imagen de soberanía y federalismo, "Continúan las observaciones sobre la desidia del gobierno general", Gaceta de Buenos Aires, Buenos Aires, 28 de marzo de 1821. Véase además del mismo periódico, "Nota", 11 de abril de 1821; "Continúan las observaciones sobre la facción federal", 2 de mayo de 1821. "Comunicación entre el Exmo Sr. General Ramírez y Doña María Retazos”, Doña María Retazos, Buenos Aires, 13 de mayo de 1821, y con el mismo título, 16 de junio de 1821. Del mismo periódico, "Continúan las comunicaciones del Supremo Ramírez con Doña María Retazos", 26 de mayo de 1821.
} 
de esta ciudad" incluyendo tanto a "españoles y extranjeros" como las fuerzas que se encuentren sin servicio. Se establece, además, que "todo el que hablare, escribiere o obrare en favor del agresor", debe entender que "será considerado reo de estado y castigado como tal." 5 Como puede apreciarse, esta batería de disposiciones está destinada a una gran movilización de toda la población, lo cual lleva a la alteración de su vida diaria (laboral, familiar, etc.) y fija pautas para la prensa y otros vehículos de propaganda (como los pasquines, panfletos, pintadas), hecho que ya venía produciendo tensiones un tiempo antes, en la medida que algunos periódicos y escritores habían sido suspendidos (son los casos de Feliciano Cavia y Francisco Castañeda). ${ }^{6}$

En otro trabajo analizo otros aspectos: la Junta de Representantes sanciona varios empréstitos forzosos con elevados montos, se exige el cobro inmediato de los llamados deudores del Estado, se presentan serios problemas para pagar sueldos de empleados, los que corresponden a los Terceros Cívicos del Cabildo dependen ahora del gobierno y no se pagan en su totalidad.7 Para completar este cuadro plagado de urgencias y de necesidades, habría que agregar aquí que el gobierno tiene que hacerse cargo de la defensa de la frontera tanto frente al chileno José Miguel Carrera como a los indios, a cargo del propio Rodríguez (entre otras cuestiones, se movilizan muchos milicianos, se pide dinero para solventarlos). Simultáneamente, se ha destacado que durante estos meses la recaudación de las reses necesarias para el pago de compensación al gobernador de Santa Fe resultaba una tarea altamente dificultosa; es de notar, además, que la provincia colabora económicamente para sostener a las tropas de Estanislao López, principal fuerza que combate contra Ramírez. ${ }^{8}$

5 Sobre todas estas medidas véase, "Bando" y "A los generosos hijos de Buenos Aires”, Gaceta de Buenos Aires, Buenos Aires, 7 de marzo de 1821.

6 Véase, "Resumen de las providencias expedidas por el Gobierno, y H. J. de Representantes de esta provincia sobre el abuso de la libertad de imprenta", Gaceta de Buenos Aires, Buenos Aires, 10 de marzo de 1821; y del mismo periódico, "Departamento de Gobierno. Decreto", 14 de marzo de 1821.

7 HERRERO, Fabián, “Conflictos políticos..., ob. cit.

${ }^{8}$ Sobre los problemas de frontera véase FRADKIN, Raúl y GELMAN, Jorge, Juan Manuel de Rosas. La construcción de un liderazgo político, Buenos Aires, Edhasa, 2015, cap. 2 y 3. López, a comienzos de marzo, informa que recibió los cinco mil pesos del gobierno de Buenos Aries que 
En suma, en segundo término, podríamos sostener que se trata de una guerra defensiva ya que estamos en presencia de una comunidad con múltiples obligaciones compulsivas, instituciones con serios problemas económicos, un escenario de conflictos locales e interprovinciales, con una población que se prepara para una probable contienda, hechos que, como bien han señalado los especialistas en guerra y revoluciones, bien pueden derivar en un cambio de poder.

\subsection{Vivir la guerra. Resistencias, temores, conflictos}

La relación entre el gobierno y los distintos actores sociales no resulta una tarea fácil en medio de la contienda bélica. Los casos de conflictos y de consensos (negociación) parecen ser fluctuantes, abiertos o con finales abiertos. En este sentido, en otro estudio he analizado varios ejemplos. Algunas comunidades extranjeras se resisten a la solicitud de movilizarse, es el caso de los ingleses que se niegan a colaborar; hay, además, tensiones entre el Gobierno y el Cabildo sobre los ejercicios militares; se toman prisioneros a federales partidarios del General Ramírez. 9

Di Meglio ha analizado varios conflictos que involucran a soldados y miembros de la plebe, que tienen derivaciones políticas. En ellos se apela a Sarratea, Ramírez, lideres federales de la revolución de octubre de $1820 .{ }^{10}$ Los casos señalados remiten a voces opositoras ligadas a la política local e interprovincial. Es de notar que no señalan cualquier aspecto sino ingredientes específicos de ese clima público: Sarratea es uno de los jefes federales que en ese momento está colaborando con la empresa bélica del caudillo entrerriano, cuyo plan es la invasión de Buenos Aires y, justamente, es evocado públicamente como uno de los posibles futuros gobernadores. La referencia a los dos líderes, entonces, no es casual ni inocente. Tampoco lo es la mención a uno de los protagonistas de la revolución federal vencida de octubre de 1820 y a los cívicos que participaron en

\footnotetext{
había pedido para el mando de su ejército. "Comunicación del Sr Gobernador de Santa Fe", Gaceta de Buenos Aires, Buenos Aires, 10 de marzo de 1821.

9 HERRERO, Fabián, “Conflictos políticos..., ob. cit.

${ }^{10}$ DI MEGLIO, Gabriel, iViva..., ob. cit., p. 228.
} 
ella, quienes también son mencionados como posibles aliados de Ramírez en la ciudad de Buenos Aires.

\section{3. Fracciones políticas, recursos, sentido de las acciones}

Los contingentes federales de Buenos Aires que, con distinta fuerza e intensidad, circulan en el espacio rioplatense, muy al contrario de lo que comúnmente se afirma, son tan amplios como variados. Pueden distinguirse dos grupos. Dentro del primero están los que operan a favor de la propuesta de Ramírez. Desde Montevideo y Colonia, hacen sus planes de corte disruptivo los partidos de Alvear y de Dorrego, quienes negocian una estrategia común y también, entre otras acciones, establecen contactos con el segundo Tercio Cívico del Cabildo de Buenos Aires. Desde Entre Ríos, donde se halla la fuerza militar de Ramírez y el chileno Carrera (que luego se va desplazando), se puede advertir a varios líderes federales locales: Manuel Sarratea, Agrelo, Santos Rubio, entre otros. Es justamente desde este último espacio donde se supone está el poder de fuego más importante. ${ }^{11}$

Un segundo grupo está integrado por líderes de partidos $\mathrm{u}$ hombres influyentes que colaboran con el gobierno o por lo menos se mantienen inactivos. El fraile Castañeda, suspendido como escritor público a fines de 1820, se le levanta la suspensión sin una justificación y, en una especie de alianza táctica, colabora en la prensa a favor de las acciones del gobierno porteño. Miguel Soler, jefe de otra de las fracciones federales en Montevideo, no se suma a la empresa de Ramírez. Según Iriarte, integrante del partido de Alvear en Montevideo, los distintos partidos

\footnotetext{
${ }^{11}$ Iriarte forma parte del partido de Alvear en Montevideo y detalla las acciones de ese partido y el de Dorrego. Tanto él como Forbes señalan lo que sucede en Entre Ríos. IRIARTE, Tomás, Memorias...ob. cit., pp. 12 y 14. FORBES, John Murray, Once años en Buenos Aires (1820-1831), Buenos Aires, Emecé, 1956, pp. 75, 114 a 118. Sobre las acciones de los partidos federales en Montevideo, Colonia y Entre Ríos, véase "Sin título", Gaceta de Buenos Aires, Buenos Aires, 24 de enero de 1821. Y del mismo periódico, "Noticia", 7 de marzo de 1821; "Carta fidedigna de un buen americano en Montevideo", 21 de marzo de 1821; "Noticias de Montevideo recibidas por cartas fidedignas", 11 de abril de 1821. Carta fidedigna de un buen americano en Montevideo", 21 de marzo de 1821; "Retazo de Entre-Ríos", Doña María Retazos, Buenos Aires, 27 de marzo de 1821. Y del mismo periódico, "Moralidad", 27 de marzo de 1821; Continúan las comunicaciones del Supremo Ramírez con Doña María Retazos", 26 de mayo de 1821; "Comunicación entre el Exmo Sr. General Ramírez y Doña María Retazos”, 13 de mayo de 1821.
} 
federales "lo evitábamos". A sus ojos, la explicación es simple, "era el único emigrado que recibía sueldo del gobierno de Buenos Aires: era la paga del espionaje que Soler ejercía." ${ }^{12}$ El caso del ex Director Juan Martín de Pueyrredón recorre un camino diferente. Exiliado en Montevideo, no participa de la empresa militar y política de Ramírez y tiene una relación ambigua con el partido del orden gobernante en Buenos Aires. Se lo vincula directamente con la administración porteña. ${ }^{13}$

Las fracciones federales locales tienen vínculos con el líder entrerriano, algunos más que otros. Todos, de una manera $\mathrm{u}$ otra, tratan de imponer representaciones en varios sentidos: sobre recursos monetarios y de hombres que supuestamente movilizan, sobre esperanzas de una victoria final, sobre planes alternativos que, entre otros, incluyen a los portugueses. La guerra, por cierto, habilita la acción política de las fracciones porteñas, activa estrategias y recursos destinados a movilizar, a orientar la voluntad de los habitantes de Buenos Aires.

En otro estudio hemos examinado las distintas cartas que se escriben desde los núcleos federales de la Banda Oriental a Buenos Aires. Se escriben a los partidarios locales; entre otras cuestiones, se habla de planes de alternativa de poder, de contingentes militares, de recursos económicos. Se trata, en rigor, de la puesta en obra de toda una red epistolar y de vínculos personales (Montevideo, Colonia y Buenos Aires). ${ }^{14}$ Las acciones colectivas están precedidas, en general, por este tipo de rumores que aluden a inminentes invasiones, se enuncian planes y se señala la cantidad de dinero para emplear y de hombres para luchar. El uso de este tipo de representaciones resume todas las arbitrariedades de las autoridades, los

\footnotetext{
12 IRIARTE, Tomás, Memorias..., ob. cit., p. 4.

13 Forbes señala en enero que muchos sostienen que "los gobiernos actuales" son considerados "pueyrredonistas". En sus notas del 17 de abril afirma que "el partido dominante ha sido acusado siempre por sus adversarios como simple locum tementes de Pueyrredón, cargo que han rechazado enérgicamente. FORBES, John, Once años..., ob. cit., pp. 78 y 107.

14 HERRERO, Fabián, “Conflictos políticos..., ob. cit.
} 
señala como los culpables de los males de la comunidad y legitima por adelantado la violencia y el cambio de poder. ${ }^{15}$

Si lo que he señalado hasta aquí es válido, se impone la conclusión de que Buenos Aires no sale tan fortalecido del año veinte. La guerra con la República de Entre Ríos paraliza las instituciones y afecta la vida cotidiana de un modo dramático, la movilización de sus habitantes, los problemas en los salarios en muchos empleados, especialmente aquellos que deben empuñar las armas, son caldo de cultivo para el "pasaje al acto" de posibles alteraciones políticas (era uno de los objetivos de los federales locales aliados de Ramírez) y un descrédito permanente del gobierno. ${ }^{16}$ Es claro, entonces, que no hay clausura del conflicto con las provincias del litoral, ni relativa paz, pero tampoco es cierto que las fracciones opositoras locales no operen en la política provincial e interprovincial. De ahí, la circulación de redes epistolares y de relaciones personales o de alianzas informales (federales locales y del litoral).

La movilización general de la población y la participación federal local de corte disruptiva no es una novedad en Buenos Aires. En febrero de 1820, ante la derrota de Cepeda del Director propietario se abre un panorama político por lo menos con estas similitudes: a partir de dos bandos, Juan Pedro Aguirre, Director sustituto, hace movilizar a toda la población (incluso llaman a inválidos y dan indulto a desertores), se manda al Cabildo acopiar víveres. Simultáneamente, Ramírez tiene como aliados a los dos líderes federales, Soler y Sarratea (finalmente lo respalda para su elección a gobernador). ${ }^{17}$

\footnotetext{
15 Sobre el uso de los rumores en acciones colectivas véase BACZKO, Bronislaw, Los imaginarios sociales. Memorias y esperanzas colectivas, Buenos Aires, Nueva Visión, 1991, pp. 35 y 37.

16 Sobre la vinculación entre la guerra y los movimientos disruptivos, véase TODD, Allan (Las revoluciones, 1789-1917, Madrid, Alianza editorial, 2000.

17 Sobre las medidas de movilización general, Gaceta de Buenos Aires, Extraordinaria, Buenos Aires, 4 de febrero de 1820. MOLINARI, Diego, iViva Ramírez!, Buenos Aires, imprenta y casa editora Coni, 1938, pp. 172-173. Sobre el federalismo local, HERRERO, F, Federalistas de Buenos Aires, 1810-1820. Sobre los orígenes de la política revolucionaria, Buenos Aires, Ediciones de la UNLa, 2009, cap. 8. PÉREZ, Joaquín, Historia de los primeros gobernadores de la provincia de Buenos Aires. El año XX desde el punto de vista político-social, La Plata, Archivo Histórico de la provincia de Buenos Aires, 1950.
} 


\section{Dos propuestas disruptivas y una nueva promesa de invasión a la provincia}

\subsubsection{El primer intento de revolución de Tagle}

En el acta oficial, fechada el 26 de agosto de 1822, el coronel Celestino Vidal, jefe del regimiento de Cazadores, denuncia ante el Gobernador Martín Rodríguez y sus Ministros (Rivadavia, de la Cruz y García), un movimiento de corte conspirativo dirigido por el doctor Gregorio Tagle, quien entre otras labores como funcionario había sido Secretario de Estado durante el Directorio de Pueyrredón. Todo se altera cuando Vidal se retracta públicamente de su declaración, dejando de esa forma al Gobierno sin pruebas concretas. Por estos hechos, se ordena la detención de los principales sospechosos. El proceso judicial es relativamente rápido, su resolución demora un poco más de un mes, se inicia en agosto y su condena se hace pública en los días finales de setiembre. ${ }^{18}$ Sin embargo, como veremos, las acciones continúan durante ese año e inclusive, se produce una nueva revolución en marzo de 1823 , donde intervienen varios detenidos del año anterior. ${ }^{19}$

El plan de acción, según el relato de Vidal, implica el derrocamiento de las autoridades. En su reemplazo, se propone para el cargo de gobernador al brigadier reformado Cornelio Saavedra, ya que uno de los propósitos del momento "era contener a los patricios, con quienes se decía" que el militar mencionado "tenía partido". Se mencionan, para el Ministerio de Gobierno al Dr. Pedro Medrano y en el de Guerra, al Coronel Mayor Juan Ramón Balcarce. No se le aclaró si estos "individuos eran o no sabedores del proyecto". Pero esto no era todo. Una vez "hecha la revolución", el otro paso consistía en la iniciativa de "restituir el Cabildo

${ }^{18}$ Sobre el acontecimiento véase, "Consideraciones sobre la conducta del coronel Vidal”, El Ambigú de Buenos Aires, Buenos Aires, setiembre de 1822, $\mathrm{n}^{\circ}$ 3. IRIARTE, Tomás, Memorias..., ob. cit., $\mathrm{p}$. 38. "Buenos Aires. Representación de la provincia", El Argos, Buenos Aires, 28 de agosto de 1822. Sesiones de la Junta de Representantes, especialmente, agosto y setiembre. "Me acaban de decir, señala Forbes el 23 de agosto, que aparte de Tagle, otras diez personas están presas". FORBES, John, Once años..., ob. cit., pp. 194 y 196. Sobre el proceso judicial, numerosos expedientes titulados "Notas del Gobierno", "Comunicaciones del Gobierno", "Ministro Rivadavia”, fechados en agosto y setiembre de 1822 en ARCHIVO GENERAL DE LA NACIÓN (AGN), Sala X, 32-1O-2. Véase El Argos de 1822, 31 de agosto; 14, 21 y 25 setiembre; 2 y 5 octubre; 9 noviembre.

19 En su declaración, José Manuel Godoy señala que lo vio a Vidal, pero luego desaparece de la escena. AGN, Sala X, 13-3-6. 
extinguido". ${ }^{20}$ Se trata, en efecto, de cortar abruptamente tanto con la línea de poder instalada en el año veinte como con una de sus reformas recientes, la eliminación de la sede capitular. Varios testimonios subrayan la importancia del acontecimiento. Un testigo señala que en el momento de su descubrimiento "este amago hizo ver al gobierno que tenía enemigos poderosos de los que debía precaverse en lo sucesivo". Otro afirma que "nadie duda que los conspiradores son muchos y poderosos", fueron "encabezados por los Pueyrredonistas y apoyados por los frailes." ${ }^{21}$ Como se ve, para algunos testigos se trata de un hecho que es percibido como relevante y reúne la adhesión de sectores distintos de la sociedad. Refuerza este argumento el hecho de que inclusive el Ministro de Gobierno intervino en la Sala de Representantes acusando directamente a Zañartu, Ministro de Chile, de "haber aconsejado y dirigido a Vidal" y por ello, es celosamente vigilado. ${ }^{22}$ El plan no resulta, en verdad, muy diferente del impulsado en marzo de 1823: también se habla de revolución, tienen nombres para reemplazar al gobierno y se menciona la restitución del cabildo. 23

\subsubsection{Militares $y$ religiosos}

Las reformas militar y del clero configuraron un terreno fértil en el que se introdujo y echó raíces la iniciativa revolucionaria. Una lógica típica de los movimientos de tipo disruptivo es que el escenario militar inicial que se levanta mezcla dos momentos y acciones diferentes: tiene por un lado algunos indicios sobre apoyos considerados seguros y planes, por otro lado, de potenciales

20 "Segunda conferencia de Vidal y las autoridades", agosto, 1822, FORBES, John, Once años...ob. cit., p 202.

${ }^{21}$ Véase, IRIARTE, Tomás, Memorias..., ob. cit., p. 38. FORBES, John, Once años..., ob. cit., p. 194. En otro informe describe un ambiente público que juzga como muy agitado: "La conocida retractación del coronel Vidal y los audaces e inflamatorios artículos de Castañeda excitaron gran indignación en ciertos círculos, pero en otros alimentan la esperanza de la caída del Ministro y la consiguiente descomposición de todo su partido.” Ibidem, pp. 196 y 197.

22 En otro informe, 2 de setiembre, afirma que las autoridades le dieron estrictas instrucciones a la policía con el fin de "vigilar sus movimientos" y advirtiendo que "si se le sorprende en cualquier actividad sospechosa, será puesto inmediatamente en la frontera." FORBES, John, Once años..., ob. cit., pp. 198 y 200.

${ }^{23}$ Se habla de "crimen de conspiración", "conjurados", y "revolución". En la declaración de José Manuel Godoy se señala que el plan "era poner en gobierno a Rolón (Mariano Benito)". AGN, Sala $\mathrm{X}, 13-3-6 .(1823)$. 
adherentes. Simultáneamente, se presentan algunos aspectos de resistencia al movimiento que hay que tener en cuenta, como los recursos materiales necesarios para solventar la empresa. Algunas de estas iniciativas son presentadas por Vidal en sus declaraciones. Sostiene que los "revolucionarios" le señalaron algunas medidas puestas en marcha: se habría llegado a "un acuerdo con varios capitanes de la Legión Patricia y también con la Caballería Patricia”. Se le señaló que "presentado él, la fuerza de su batallón no había cosa alguna que cruzase la Revolución", hecho que consideraban debía "ejecutarse cuanto antes". Se le aseguró que se "contaba con la mayor parte de la tropa y oficiales del Número 1", que esto era de esta forma porque "el señuelo de los que componían este cuerpo era de los soldados que en el año 20 habían puesto preso a su Coronel”. Se le explicó que "no querían hablar al Coronel Ramírez", porque se consideraba que "no era hombre con quien se contaba para batirse". Gregorio Tagle le había "asegurado" que en el "momento que le avisase estar listo su batallón, tendría la cantidad de 12.00o pesos a su disposición" con el propósito preciso de "gratificar la tropa." $24 \mathrm{La}$ cifra parece importante, si tenemos presente que son los mismos recursos que durante el año 1821 necesitó el Gobierno para solventar el sueldo de los cívicos de la ciudad. Estos preparativos resultan similares a la revolución de 1823, en cuanto se menciona como un tema importante la recaudación del dinero y se advierten dificultades para obtenerlo. ${ }^{25}$

Otra lógica habitual en los fenómenos de este tipo es que bien puede desactivarse el movimiento una vez capturado sus máximos responsables, o bien puede advertirse acciones que muestran que el movimiento sigue su curso. Se sigue aquí la huella de la segunda escena. Entre otros ejemplos, se señala que además de Vidal "el mayor del Regimiento, Don Ramón Rodríguez, también ha sido destituido por haber encontrado manera de conversar con Tagle" y lo hizo precisamente

24 "Segunda conferencia de Vidal y las autoridades", agosto, 1822, FORBES, John, Once años..., ob. cit. p. 202.

25 Declaración de José Manuel Godoy. Se colectaron dinero "dos mil pesos”, “Achega dio 1000 pesos". Declaración de Tomas Rebollo, cuenta que le pidieron 14000 pesos a Tagle pero no se los dio. $A G N$, Sala X, 13-3-6. 
“después de declarado éste incomunicable." 26 No es casual tampoco que el comandante del presidio sea denunciado por facilitarles las cosas a los detenidos. Se abrió un sumario por una denuncia anónima dirigida contra su comandante, donde "se comprueban los hechos anunciados en la carta (anónima) que se reducen a haber recibido aquel comandante gratificaciones pecuniarias por la libertad de algunos presos. ${ }^{27}$

Tensiones, conflictos en el área militar, suelen ser los motivos que generan movimientos disruptivos. En este caso, la participación de militares encuentra razones sustantivas en las consecuencias de la ley de reforma reciente. Es justamente lo que menciona un testigo de los hechos al señalar que Tagle disponía de "algunos jefes reformados" que estaban "descontentos" por los últimos cambios en el ejército. ${ }^{28}$ La reforma consistió, según menciona otro asistente a los hechos, en una "radical reducción del establecimiento militar". ${ }^{29} \mathrm{El}$ decreto fue firmado los últimos días de febrero de 1822, el cual dispone que "se dan de baja del servicio, con media paga durante veinte años" a oficiales de distinto rango. De los tres brigadieres generales que cita la ley, dos son sospechados de conspiradores: Pueyrredón y Saavedra. ${ }^{30}$

En una mirada rápida de los expedientes sobre reformados pueden verse distintas realidades. Militares que solicitan el "sueldo íntegro de su clase", puntualizando los detalles de su labor. Es el caso del Coronel reformado D. Xavier Aparicio o el del Sargento Mayor D. Luciano María Cabral que, en tono de angustia, "suplica" se ordene su "pago en consideración de las necesidades que padece su familia" ya que "un militar no puede contar con otro recurso". Otra situación es la

${ }^{26}$ FORBES, John, Once años..., ob. cit., p. 196. En su informe de 27 de agosto sostiene que "un sargento de los cívicos o milicia, y tres sargentos se han entregado presos" y todos han confesado ser “cómplice de la conspiración." Ibidem, p. 174. Por esos días en El Argos se reprodujo "la denuncia contra un sargento de cívicos de haber tratado de seducir a algunos para hacer una revolución”, con este fin ofrece como "pretexto que se trataba de sortearlos para completar el ejército".

${ }_{27}$ El jefe policía, agrega que "estaba persuadido de la mala conducta”. "Exposición del jefe de policía, 6-9-1822." AGN, Sala X. 12-5-8.

28 IRIARTE, Tomás, Memorias..., ob. cit., p. 56.

29 FORBES, John, Once años..., ob. cit, pp. 196 y 197.

30 Ibidem, p. 174. 
de aquellos que, por un lado, son separados de un empleo por la reforma y, por otro, se hace un reclamo porque se considera que dicho trabajo es "necesario". Es el caso del Ayudante Mayor D. Inocencio Pérez. ${ }^{11}$ Los signos de malestar también resultan evidentes si se miran las actas de las sesiones del ámbito legislativo. En algunas de las realizadas durante el mes de agosto, por dar un solo ejemplo, se presentan militares que pretenden que se les pague como militares reformados y no se hace lugar. $3^{2}$

Tanto en la revolución que analizamos como la que ocurre en marzo de 1823,33 la conspiración y la reforma eclesiástica no van por carriles diferentes. Es lo que justamente sostiene Forbes, al afirmar que estas "piadosas criaturas no han sido indiferentes ni pasivos espectadores de la conspiración." Por el contrario, y aquí nuevamente aparece la imagen no casual del terror, su "extensa influencia e infatigable actividad infunden una atmósfera de terror al abortado movimiento.” Y en forma concluyente señala que "nadie hubiera osado dar un solo paso, de no haber contado con su alianza y cooperación." 34 Los religiosos, a los ojos del diplomático norteamericano, resultan una pieza clave en este movimiento. En los primeros meses de 1822, se producen distintos tipos de conflictos relacionados con ellos, los cuales producen en algunos casos la expulsión de la provincia. En los legajos de policía es posible advertir varios casos de curas que, por distintas causas, son intimados y expulsados de la provincia. 35

Visto el tema desde la óptica más próxima al gobierno se impone un problema histórico: las consecuencias derivadas de la mirada sobre el otro que resiste la reforma. La mirada que yo tengo del otro, como ha demostrado Todorov,

\footnotetext{
${ }^{31}$ Se crea una plaza de ayudante de teniente, el único reparo es la "calidad de reformado que tiene el propuesto". AGN, Sala X, 12-10-1. Casos similares pero de policía ver Sala X, 12-5-8. Para su solicitud se señala que se presenta "documentos que acreditan sus servicios". Hay casos donde se reclama que "no se halla en caso de la Ley de retiro", es el caso de D. Ramón Palacios.

$3^{2}$ Acuerdos Junta de Representantes, Sesión 21 y 23 de agosto de 1822.

33 En varios expedientes de la revolución de 1823 se señala que Tagle dispuso de militares y religiosos. Tomas Rebollo cuenta además que contaban "con los carretilleros" y la "caballería nacional”. AGN, Sala X, 13-3-6.

34 FORBES, John, Once años..., ob. cit., p. 195.

35 Véanse varios expedientes del mes de marzo, abril y mayo de 1822, bajo el título "Comunicación del gobierno", AGN, Sala X, 32-1O-2.
} 
determina un tipo de acción sobre él. Como veremos a continuación, la presencia de una retórica que cuestiona a hombres de la iglesia (como analizaremos en el caso de El Lobera), determina una forma de actuar, el castigo, lo cual se advierte en las acciones judiciales. En este preciso sentido, hay que decir que desde la prensa que promueve la reforma del clero pueden leerse distintos tipos de actos de indisciplina del clero que, a los ojos oficialistas, justificarían el diagnóstico reformista de los ministros y su tarea legislativa al respecto, así como ciertas acciones en la justicia. El caso más notorio, por cierto, es El Lobera, tribuna periodística que será llevada a juicio por dar nombres de los implicados y tener un lenguaje juzgado como violento. ${ }^{36}$ Lo que se advierte aquí es la cuestión sustantiva de la difamación política. Esta tiene su lógica. La anécdota o mínimo relato que se enuncia debe ser contado de un modo comprensible rápidamente y se apunta a la reputación del otro. El mensaje debe simplificar lo que aparece como un contenido complicado de interpretar o complejo: a favor o en contra de la reforma del clero o de los ministros; (como veremos en Castañeda), a favor o en contra de los religiosos viciosos (es el caso de El Lobera). Se trata de un mensaje que intenta polarizar la opinión. ${ }^{37}$ Señalo algunos botones de muestra. El provincial de Santo Domingo, Frai Mariano Suarez, vive en una "casa comprada con limosnas de los fieles", Fr. Ignacio Grela tiene "hijos" de "distintas madres", en el presente "está amancebado con una mujer casada", su marido apeló al Provisor, quien "no ha podido" de ningún modo "conseguir la separación de este lascivo fraile, y sigue en la misma ida." El cantor de la Catedral, Fray Juan Moreno, tiene "dos hijos de su amiga la Pascuala, con quien públicamente vive, llamados Marcelino y Anselma”, al mismo tiempo, es señalado como "más prostituido que Lutero, inmoral en sentido sublime, ladrón, borracho, hablador.” Fr. Jorge Aparicio es acusado de "amancebado, libertino, jugador, mal amigo y peor hermano.” Fr. Manuel Cuitiño es descrito como un hombre "de padres desconocidos, plebeyo, asesino, sin moralidad, sin costumbres", alguien, en fin, que "entró a fraile porque no conocía

36 "Los frailes, señala Forbes con relación a este diario, son designados con todos sus nombres, lo mismo que el de sus queridas e hijos, se les acusa abiertamente de homicidios, robos, embriaguez y libertinajes de toda especie.” FORBES, John, Once años..., ob. cit., p. 204.

37 DARNTON, Robert, Los best Sellers prohibidos en Francia antes de la revolución, México, FCE, 2008, pp. 239, 241, 368. 
ocupación, ni tenía que comer." ${ }^{8}$ Este tipo de difamación no cayó en balde, tiene su correlato tanto en el ámbito legislativo con las reformas, como en el dominio judicial. Entre los meses de julio en adelante, se ha señalado varios expedientes en donde se advierten casos tratados por el gobierno donde frailes y monjas de la iglesia son acusados de distintos actos de indisciplina, entre otros, de juerguistas o de tener hijos. 39

En suma, se conjugan aquí problemas de diversa índole: de facciones, en cuanto se enfrentan un grupo ex centralista en el poder y otro del mismo signo en su intentona revolucionaria, más allá de que es probable que de una forma u otra hayan participado también miembros de otros partidos, ${ }^{40}$ hecho que parece repetirse de algún modo en la que se produce en marzo de $1823 ;^{41}$ de elite, en cuanto (una vez más) no pueden ponerse de acuerdo los líderes de la elite política; de cambios disruptivos, en la medida que se produce aquí una segunda iniciativa de revolución, esta vez de otro signo ideológico, lo que muestra que desde distintas tendencias se produce este tipo de conflicto.

\subsection{El fraile Castañeda propone una contrarrevolución}

La actuación del franciscano reconoce varias acciones: la presencia de redes

38 "Miscelánea” y “Comunicados. Aviso Primero", El Lobera del año 20, o El verdadero ante-cristo (en adelante El Lobera), Buenos Aires, 23 de setiembre de 1822. Del mismo periódico, 3 de octubre de 1822: "Notable"; "El verdadero Fraile o el Espejo de la virtud"; "Recoletos o Santos Maragatos"; "El verdadero Fraile o el Espejo de la virtud"; "Pasaje"; "Dominicos o engendradores", "Recoletos o Santos Maragatos", "Notable".

39 Varios expedientes de este tipo pueden consultarse en AGN, Sala X, 4-8-3. Otro caso es el de la monja Sor Vicenta Álvarez, acusada de frenética, quien "se arroja a los claustros" y "escandaliza tanto con sus acciones y palabras". Hechos señalados por MYERS, Jorge "Las paradojas de la opinión. El discurso político rivadaviano y sus dos polos: el gobierno de las luces y la opinión pública, reina del mundo", en Hilda SABATO y Alberto LETTIERI (comp.), La vida política en la Argentina del siglo XIX. Armas, votos y voces, Buenos Aires, FCE, 2003, pp. 80-83.

40 Un testigo señala que "Dorrego tenía un círculo aparte" al de "Tagle", sin embargo, "trabajaba en el mismo sentido contra el gobierno". El líder federal se había constituido en jefe del partido que antiguamente había liderado Soler. Finalmente, al descubrirse la conspiración su situación cambió, “Dorrego que estaba complicado, no apareció.” IRIARTE, Tomás, Memorias..., ob. cit., p. 38 y 56.

${ }^{41}$ Declaración de T. Rebollo, sostiene que el "coronel Rolón le aseguró repetidas veces que estaba en la inteligencia para la misma conspiración con el coronel Dorrego, D. José Bares y D. Epitacio Campos". Sin embargo, en la "Orden del Día”, firmada por Rivadavia, 23-3-1823, hay otra versión. Agradece a los militares que estuvieron del lado del orden, entre ellos cita a Manuel Dorrego y Carlos Alvear. AGN, Sala X, 13-3-6. 
interpersonales, la edición de periódicos de tono opositor en las cuestiones relacionadas con la reforma del clero y los ministros reformistas y, entre otras cuestiones, una iniciativa de línea rupturista.

\subsubsection{Un hombre "popular" con maneras de actuar disruptivas}

Castañeda bien puede asimilarse a la figura del activista político y social de las zonas marginales de la ciudad. Un testigo ha señalado que "fuera de sus actividades periodísticas", se lo ha visto "caminando por los suburbios de la ciudad, descalzo, vistiendo hábitos sucios, y esgrimiendo en sus manos una cruz", concluyendo que, por "su vulgaridad y familiaridad, cautiva fácilmente al populacho." 42 Según esta perspectiva, puede ser visto como una amenaza latente de probables levantamientos de los sectores más desposeídos, al adoptar la forma y el lenguaje del "terror" y del "populacho". Desde El Lobera, en una línea similar, se afirma que "los periódicos puercos de este fraile, han puesto al padre contra al hijo", al "subalterno a su jefe".43 En esta escena de desorden, de disolución de los lazos jerárquicos, de autoridad, no es extraño que se asegure que el franciscano "ha llegado al extremo de proponer" al "Provisor de la Catedral, que ordene el cierre de todas las iglesias y declare al Gobierno en un estado de excomunión." Hecho que fue rechazado por el Provisor y que "hubiera desatado a las clases bajas y provocado una masacre general." 44

Lo dicho hasta aquí hace del todo verosímil la imagen del conspirador y del faccioso.45 Toda una red de correspondencia y vínculos personales son reproducidas con frecuencia en las páginas de El Lobera. Se puede leer allí que

42 FORBES, John, Once años..., ob. cit, p. 195.

43 "Sin Título", El Lobera, sin fecha. También, "Cuartetos a la derniere en honor del R P definidor Fr Francisco Castañeda”, El Lobera, 3-10-1822.

44 "Sus escritos sediciosos", lo califica Forbes. FORBES, John, Once años..., ob. cit., p. 195. En su informe de 29 de agosto de 1822, "el padre Castañeda, movido por su éxito momentáneo llegó a la increíble temeridad de llenar la ciudad de cartelones provocativos, incitando al pueblo somnoliento a despertar y defender su religión, contra un gobierno de herejes." Ibidem, p. 197.

45 Castañeda "es trompeta de una facción bien conocida", es "su mejor instrumento", "trabaja activamente en llevar adelante sus planes." "Deducción correcta del anterior Paz Christi”, El Lobera, Buenos Aires, 23 de setiembre de 1822. En otro lugar sostiene, "iLobera! lo sabemos comprendido en el plan frailesco-gavillante." "A Castañeda”, El Lobera, 3 de octubre de 1822. 
envía supuestas cartas de tono conspirativo a actores diversos, desde un poderoso monarca europeo a un dirigente político provincial, como "el gaucho gobernador de Santa Fe", pero también a religiosos y a los distintos líderes de la conspiración de Tagle y Pueyrredón. Sus fines, según esta perspectiva, son tan diversos como negativos: sembrar la anarquía, aprovechándose del "pueblo ignorante", hasta incentivar a que se ridiculice a los funcionarios del gobierno. ${ }^{46}$

Hay una carta en particular, fechada el 26 de junio de 1822, que está supuestamente firmada por el franciscano, en la que cuenta sus días de presidio en Kaqueluhincul. Está dirigida a otro religioso, descrito de este modo, “Al R. P. Fr I. G”. Podría tratarse de Ignacio Grela, ya que las iniciales concuerdan con sus datos y además es uno de los hombres de la iglesia cuestionado por El Lobera. Aquí el fraile es presentado directamente como un activo militante antirreforma que forma parte de la conspiración de Tagle.

\begin{abstract}
"Compañero y querido Ignacio: la adjunta que te remito, es para nuestro buen amigo, y el mejor y más notable de los porteños Juan Martín [se refiere al ex Director Pueyerredón]; y creo que ya habrás puesto en mano la que anteriormente te dirigí, para el ilustre y sin igual Gregorio [alude a Tagle]...conseguiremos no lo dudo el derribamiento de esos canallas para que volvamos al orden antiguo que nos conviene (...) tenemos para ello una gran oportunidad con la quitada del Cabildo y la reforma eclesiástica; ganen ustedes terreno, que la mayoría está por nosotros. Trabajar bastante con los amigos. Eh, me comprende? Da memorias a Fr. Cayetano [se refiere a Rodríguez, redactor del diario Oficial del Día], y dile, que en caso necesario haga valer la opinión que tiene." 47
\end{abstract}

Si como advertimos ya, el franciscano es parte de un plan de conspiración en marcha, en este pasaje se destacan los motivos que hacen supuestamente posible esta empresa, las consecuencias de la abolición del Cabildo y la iniciativa de reforma del clero; al mismo tiempo, se hace notar que no es una acción de hombres aislados, sino de un perfecto plan donde hay "amigos" que actúan coordinadamente, en forma de red. El cuestionamiento de El Lobera mezcla elementos que juegan entre lo que se puede o no creer. En este sentido, es de notar que; Cayetano Rodríguez; escribía en un periódico de tono opositor y también,

46 "Correspondencia interceptada-Buenos Aires”, El Lobera, sin fecha. "Observación”, El Lobera, 23 de setiembre de 1822.

47 "Otra”, El Lobera, Buenos Aires, sin fecha. 
finalmente, se le levanta un sumario acusado de ser un escritor "impostor". 48

La imagen de Castañeda como faccioso, conspirador, activista político y social de las zonas urbanas más pobres; se completa de alguna manera con la del escritor popular. Varios motivos son mencionados al respecto. En primer lugar, sus adversarios lo perciben de este modo. El Lobera señala que se apoya en "la plebe, los viejos, y las mujeres", quienes forman "su numeroso séquito." $49 \mathrm{El}$ general Iriarte; destaca la eficacia de su escritura y su resonancia en los sectores desposeídos, al sostener que son "celebres sus trabajos literarios", los cuales "se leían con avidez, principalmente por las clases ínfimas del pueblo". $5^{\circ}$ En segundo término, Nancy Calvo ha señalado la posible "independencia" de sus empresas periodísticas al afirmar que tanto la venta de los ejemplares como la limosna podían contribuir a solventarla. $\mathrm{Y}$, en tercer término, el hecho de que fuera electo representante en la primera elección realizada con la ley electoral de 1821 que estableció el sufragio amplio, puede ser también un buen indicador de que ha sabido cosechar adeptos. ${ }^{51}$ Resumiendo, es presentado como parte de una facción, actuando como sedicioso y conspirador e interviniendo a partir de redes, pero también se lo vincula con la plebe, las mujeres y, atravesando la frontera, con el gobernador de Santa Fe.

\subsubsection{Propuesta}

En la visión del fraile, el gabinete ministerial, entre otras irregularidades, actúa de forma arbitraria, ya que a través de él, el gobierno ejerce el doble papel de

${ }^{48}$ Se pide al gobierno que se "sirva mandar formar la acusación respectiva por quien corresponda al autor del periódico intitulado el Oficial del Día como falso impostor” por expresiones vertidas allí. "Nota al gobierno", 20 de setiembre de 1822. AGN, Sala X, 12-5-8.

49 "El Ante Cristo a sus secuaces o enemigos del nuevo Mesias" y "Advertencia oportuna y necesaria, para la anterior inadvertida conclusión”, El Lobera, Buenos Aires, sin fecha. Sobre la importancia de las mujeres en el discurso de Castañeda, TROISI-MELEN, Jorge, "Redes, reforma, y revolución: dos franciscanos rioplatenses sobreviviendo al siglo XIX (1800-1830), Historia Sacra, 122, juliodiciembre, 2008, p. 481.

50 IRIARTE, Tomás, Memorias..., ob. cit., p. 250. Feliciano Cavia, en Las Cuatro Cosas, sostiene que el franciscano "tiene cuatro o cinco periódicos" y para ello dispone de la "ayuda de muchos vecinos."

${ }^{51}$ Sobre la imagen de Castañeda como periodista popular ver el excelente trabajo de CALVO, Nancy, "Voces...", ob. cit., pp. 575-596. Las menciones corresponden a Las Cuatro cosas, Buenos Aires, 3 de febrero de 1821; Paralipómenon al Suplemento del Teofilantrópico, Buenos Aires, $\mathrm{n}^{\circ}$ 8. Diario de sesiones de la Junta de Representantes. 
"acusador y parte", por ejemplo, cuando "nombra el consejo de guerra que ha de sentenciar". Lo prueba, además, el hecho que como "actúo con Vidal", también "actúa con los regulares". $5^{2}$ A partir de este diagnóstico sombrío, se comprende por qué en agosto pone en duda que sea ilegal pedir al respecto una sedición.53 En setiembre, en el contexto de la revolución de Tagle afirma que "si por fortuna hubiese estado yo en la honorable Junta Argentina" justo en el momento en que el "Sr. Ministro Bernardino Rivadavia dio cuenta a la Sala de la conjuración”, hubiese expuesto que "era indispensable que inmediatamente se procediese a la prisión del ministro mensajero". 54

$\mathrm{Su}$ propuesta gira en torno a un movimiento de renovación del elenco gobernante. Al excluir de la esfera del poder a los ministros "despóticos", se trata, en rigor, de hacer "una contra-revolución" que "fijaría el Gobierno de Martín Rodríguez, a quien el pueblo todo compadece y a quien no deja de amar, aun después de tantos sinsabores y disgustos" $55 \mathrm{El}$ vocabulario, nos los recuerda Baczko, no es jamás una "herramienta neutra", proyecta, en efecto, su "sombra sobre el pasado al que se le aplica”. Los trabajos disponibles sobre el tema señalan que la noción de contrarrevolución figura en el vocabulario político de Buenos Aires, por lo menos con dos acepciones: como una iniciativa pro española que resiste o pretende derrocar los gobiernos impulsados desde la revolución o bien como un movimiento con elementos del propio estado para modificar algunos integrantes del gobierno. La conspiración de Alzaga de 1812 ilustra el primer caso,

$5^{2}$ Véase "Carta" y "Comunicado", La Verdad Desnuda, Buenos Aires, n 3, 7 de octubre de 1822. Sobre los mismos argumentos consultar, La Verdad Desnuda, Buenos Aires, $\mathrm{n}^{\circ}$ 4, 18 de octubre de 1822; Prospecto, La Guardia vendida por el Centinela y la traición descubierta por el oficial del día, Buenos Aires, 28 de agosto de 1822.

53 En términos potenciales se sostiene en uno de sus diarios que a partir de una "solicitud del clero y pueblo" (como se ve, se adjudica la representación de ellos), si es posible considerar "sedición el pedirle al Gobernador, Martín Rodríguez, o a la Honorable Soberana Junta (de Representantes)" que ponga a "Rivadavia en la cárcel de acreedores, o deudores, donde está el Dr. Tagle, o en la Fortaleza donde está Celestino Vidal”. La Verdad Desnuda, Buenos Aires, 24 de setiembre de 1822.

54 "Comunicado", La Verdad Desnuda, Buenos Aires, 7 de octubre de 1822. En este mismo ejemplar se señala, "nadie tiene la culpa sino el ministro de la perturbación de la tranquilidad pública y de los males que esta debe acarrear a la comunidad, en virtud de que la perturbación emana en su origen del proyecto de leyes y decretos expedidos contra las leyes, sentimiento y opiniones de la sociedad.". Véase también, "Retazos para la historia de la persecución del clero en Buenos Aires", Doña María Retazos, Buenos Aires, 5 de octubre de 1822.

55 La Verdad Desnuda, Buenos Aires, 24 de setiembre de 1822. 
el segundo alude a la experiencia de Juan Ramón Balcarce en abril de 1820. Exactamente, el Gobernador Manuel Sarratea, en esa intentona rupturista del orden, denunciaba que este militar estaba organizando una contrarrevolución con elementos humanos y materiales del estado de Buenos Aires. ${ }^{6}$ Se trataría, para decirlo directamente, de un movimiento de fuerza organizado desde el mismo círculo del gobierno provincial para retomar las riendas del poder.

En el caso del fraile, lo que impulsa es un movimiento similar a este último caso, pero esta vez protagonizado por un Gobernador a quien percibe débil y dominado por sus ministros. Es a él a quien le corresponde, entonces, tomar verdaderamente el poder desplazando a los funcionarios que impulsan la reforma del clero. En suma, Castañeda promueve una "contra revolución" que surge de hombres del gobierno y aliados contra funcionarios del propio gobierno. Por este orden de razones, se comprende por qué propone que "Rivadavia sea juzgado rigurosamente", por "cualquiera otra conjuración que sobrevenga." 57 Se refiere obviamente a su iniciativa de contrarrevolución. Esta parece ser la raya que no debía cruzar. Luego de esta propuesta de contrarrevolución y su defensa de Vidal, el franciscano es acusado de injuriar al gobierno y va a juicio. Es de resaltar que, además, tiene abierto otro sumario por supuestas injurias a un subordinado del departamento de policía. ${ }^{8}$

\subsubsection{Las posibilidades de la propuesta y la red de relaciones personales}

${ }^{56}$ Sobre el primer uso, PÉREZ, Mariana, “iViva España y mueran los Patricios! La conspiración de Alzaga de 1812”, en M. ALABART, M. A. FERNÁNDEZ y M. PÉREZ, Buenos Aires, una sociedad que se transforma, Buenos Aires, Prometeo, 2011. Sobre el segundo, HERRERO, Fabián, Federalistas..., ob. cit., véase en particular cap. 8. Sobre la noción del vocabulario, véase BACZKO, Bronislaw, Los imaginarios sociales. Memorias y esperanzas colectivas, Buenos Aires, Nueva Visión, 1991, p 17.

57 “Comunicado", La Verdad Desnuda, Buenos Aires, 7 de octubre de 1822.

${ }^{8} \mathrm{El} 29$ de octubre el jefe de policía, Joaquín Achaval se dirige al ministro Rivadavia señalando que "en el n 5 del periódico La Verdad Desnuda (de F. Castañeda) acabo de ver un comunicado sin fecha de un sujeto que se intitula Un pobre de espíritu en que acusa la conducta e integridad del subalterno del departamento que está a mi cargo en cuya mesa se lleva el registro de las marcas de los hacendados". El 19 de noviembre finalmente se resuelve que "el subalterno" sea exculpado, considerando que "esto sucedió seguramente por el traspapelamiento de algún apunte, pero que atendiendo a la pequeñez de la cantidad y a la conducta del subalterno puede pasarse al jefe de la policía para que lo suspenda de su empleo o lo aperciba seriamente.” AGN, Sala X, 12-6-6. 
El movimiento de contrarrevolución nunca se concretó. Es muy probable que el inicio del juicio a Castañeda haya sacado de escena a uno de sus principales protagonistas. Lo que sí es posible conocer son algunos indicios sobre los actores a los que apela o bien aquellos que son presentados como parte de esa acción disruptiva, datos que pueden ayudarnos a entender, a su vez, en qué basaba su optimismo sobre sus probables chances de triunfo. Veamos, en efecto, cómo se presenta formando parte de una red de relaciones personales que vincula a distintos actores poder.

Fuerzas armadas. Se adjudica el apoyo de los que llama "héroes porteños", aquellos militares que defienden al "clero secular y regular", entre los que figuran el actual Gobernador de la provincia, dos de los líderes de una fracción política de la actual resistencia, Pueyrredón y Vidal, pero también otros que figurarían como el nuevo gobierno propuesto por la revolución de Tagle y, finalmente, actores como Rosas, que no se pronuncia sobre nada de lo que ocurre, hecho que bien llama la atención en cuanto está distanciado con el gobernador por el tema de la frontera.59

Vicario Capitular del Obispado. En el juicio que se le inicia por esos días señala que en los meses previos se encontraba en los desiertos parajes de Kaquel Huincul. Vuelve a la ciudad por pedido del "Sr Provisor del Obispado Dr Mariano Medrano", quien en el mes de julio le señala que es "de necesidad tuvieran una entrevista." En ese encuentro, "su Señoría”, continúa su razonamiento Castañeda, "le suplicó y aun le mandó que siquiera hasta mediados de octubre permaneciese en la contienda con tanto tinterillo palangana que estaban faltando al respeto debido al público". 60 El fraile, entonces, no interviene por las suyas y de forma

\footnotetext{
59 Le pregunta a sus lectores "decidme: un Martín Rodríguez, un Martín Pueyrredón, un Cornelio Saavedra, un Juan Ramón Balcarce, un Rondeau, un Viamonte, un Cruz, un Vidal, un Rosas, un Irigoyen, y todos esos innumerables caballeros que se opusieron... [a] rendirse a la montonera ¿serían capaces de desenvainar la espada contra un eclesiástico, aun cuando fuesen provocados? No, por cierto, porque el militar honrado, el héroe verdadero no se bate jamás con el que a su espada no puede oponer otra espada". "Sin título", Doña María Retazos, Buenos Aires, 20 de setiembre de 1822. Un periódico critico a Castañeda, lo cuestiona porque ha "ensalzado de héroes, de únicos, y de sabios a Pueyrredón y a Tagle. "Sin Título", El Lobera, Buenos Aires, sin fecha.

6o Y agrega, que "los sabios que podían contenerlos, no querían alternar con hombres tan indecentes, ni exponerse a la lluvia de sarcasmos, como se expuso el M.R.P. Jubilado, ex Provincial Fr. Cayetano Rodríguez, por sólo haber dicho que un papel indecente dado a luz con las iniciales de
} 
Voces de invasión e iniciativas disruptivas...

aislada, se percibe como una especie de intermediario del Vicario Capitular del Obispado.

Gobernador. El padre franciscano asegura ser un "acérrimo defensor de la administración presente”. Su actitud no es nueva. Refiriéndose a su batalla en la prensa con los federales locales hace notar, por ejemplo, que los porteños conocen bien que "con sus escritos semijocosos contribuyó mucho a sostenerla en el año XX". Así puede jactarse de decir "que en gran parte la mira como una obra de sus manos". Dentro de este contexto, señala que desde que llegó a Buenos Aires, "no ha cesado de remitir cartas reservadas al Sr. Gobernador noticiándole de varias coaliciones para que estuviese prevenido", pero eso no es todo, el "Sr Gobernador lo llamó una noche a una conferencia verbal sobre éstos y otros asuntos."61 Recordemos que Rodríguez tampoco se expresa públicamente sobre los acontecimientos disruptivos señalados aquí, hecho que por lo menos no desmiente los dichos del fraile.

"Partido de Pueyrredón". Castañeda, durante el Directorio de Pueyrredón, fue uno de los hombres de la iglesia que tuvo repercusión pública e incluso, en varios de sus oficios religiosos, aquél estuvo presente. Durante el año 1820 la llamada "facción pueyrredonista" estaba totalmente desacreditada. El franciscano es una de las pocas voces que lo respalda: "por no ser montonero", afirma de modo desafiante, "yo también quiero ser Pueyrredonista y Saavedrista." ${ }^{2}$ No dejemos

su nombre, no era suyo". "Segunda declaración de Francisco Castañeda", octubre de 1822, citado en FURLONG, Guillermo, Vida y obra de Fray de Paula Castañeda: un testigo de la naciente patria argentina: 1810-1830, Buenos Aires, Editorial Castañeda, 1994, p. 680.

61 "Segunda declaración de Francisco Castañeda", octubre de 1822, citado en FURLONG, Guillermo, Vida..., ob. cit., p. 681. Forbes, en su informe del 16 de marzo de 1821, señala que el "Entre el material impreso acompañado se encontrará una segunda queja del coronel marcos Balcarce, últimamente gobernador delegado, contra el perverso sacerdote libelista, el Padre Castañeda, quien lamento decirlo, goza demasiado crédito e influencia con el actual gobernador (se refiere a Martín Rodríguez).” FORBES, John, Once años..., ob. cit., p. 97. Incluso hacia finales de los años 20, Iriarte recuerda un episodio donde comparten charlas y bromas el franciscano y Rodríguez. IRIARTE, Tomás, Memorias..., ob. cit., p. 249.

62 "Advertencias que deben tenerse muy presentes para evitar toda equivocación en cuanto yo dijere concerniente a la persona de D. Juan Martín de Pueyrredón”, Paralipómenon del Suplemento al Teofilantrópico, Buenos Aires, n. 6. Véase también el n. 5. En una proclama revolucionaria de los federales de octubre de 1820 vinculan al ex director con el fraile de forma directa, al señalar como a uno de sus enemigos al "infame y declarado faccionalista de Pueyrredón el fraile Castañeda", "Proclama consiguiente al ataque nocturno de los montoneros de adentro." El Despertador, Buenos Aires, 12 de 
pasar por alto que Saavedra es el que supuestamente reemplazaría a Rodríguez si hubiese triunfado la conspiración de Tagle. En esta línea, no sorprende entonces que pida que el ex director vuelva a la arena política local. "El sr. Brigadier Juan Martín Pueyrredón" debe "cuanto antes restituirse a su pueblo para confusión de los federimontoneros tanto porteños como provincianos", de quienes "nos libre Dios para que no se repita...el año veinte" o bien que lo califique como "los héroes porteños, Pueyrredón y Tagle....". ${ }^{63} \mathrm{Y}$ no sorprende porque, como se ha visto ya, tanto Pueyrredón como Tagle figuran entre los "héroes verdaderos" que el fraile señala en los tiempos duros de la ley de reforma religiosa. Es muy probable pensar, también a modo de conjetura, que Castañeda sea un miembro o bien un adherente del grupo pueyrredonista, pero sin decirlo abiertamente. Es lo que señala de alguna manera Iriarte, cuando sostiene que aquél "escribió siempre con tendencia a acreditar aunque con el mayor disimulo, al partido caído del directorio, hacia el que era manifiesta su parcialidad.” 64

Llegados a este punto bien podría decirse que el imaginario social en el que se mueve Castañeda tiene varias funciones: designar al enemigo, los ministros reformistas; movilizar energías, lo hace hacia abajo, los sectores menos visibles mujeres y plebe y los espacios suburbanos- y hacia arriba, los principales miembros del gobierno, iglesia y armas; difundir temores (se derrumban los valores de la iglesia) y esperanzas (la contrarrevolución). Todas convergen hacia la legitimación del cambio del gobierno. ${ }^{65}$ Resulta difícil de constatar el alcance de esta propuesta. En rigor, sí muestra, sin lugar a duda, un aflojamiento de los hilos sociales y de poder. Al mismo tiempo, se imponen preguntas que quedan abiertas y agregan sospechas: ¿Por qué Rodríguez y Rosas, quienes son nombrados en la escena pública como posibles participantes de estos hechos, sin embargo, no se expresan públicamente? ¿Por qué se vincula a Castañeda como conspirador ligado a la restitución del Cabildo

octubre de 1820. En el mismo número del diario, en una nota aclaratoria, el franciscano le contesta, "Ser pueyrredonista por no ser anarquista es lo fino de la prudencia, y de la política." También en "Sr Teofilantropico", El Despertador, Buenos Aires, 14 de octubre de 1820.

${ }_{3}$ Sin título, El Desengañador, Buenos Aires, n. 18.

64 IRIARTE, Tomas, Memorias..., ob. cit., p. 250.

65 Sobre las funciones del imaginario social, véase, BACZKO, Bronislaw, Los imaginarios..., ob. cit., p. 34 . 
y a Estanislao López, poniendo, otra vez sobre la mesa pública, conflictos supuestamente resueltos?

\section{Espacios de conflictos y redes de fracciones. Algunas conclusiones}

1. A lo largo de este trabajo lo que he tratado de avanzar a modo de hipótesis, es que la oleada reformista que afecta a autoridades (Cabildo), territorios (expansión frontera y política con los indios), sujetos e instituciones (reformas del clero, militar, imprenta) no se dio en un clima de relativa paz y de ausencia de facciones, por el contrario, ocurrió en una escena abierta y dinámica atravesada y rodeada por distintos movimientos de redes, de grupos y fracciones políticas, con vocación de poder (por vía armada o electoral) y espacios de conflicto y de tensión, y con problemas históricos que no parecen haberse cerrado al finalizar la crisis de 1820.

Espacios y momentos de movilización: en primer lugar, durante la guerra con la República de Entre Ríos se moviliza a una importante parte de la población, surgen espacios de conflictos entre autoridades (gobernador y Cabildo), de resistencia (comunidad inglesa), crisis del erario. En segundo lugar, en los años 1822 y 1823 hay movilizaciones en el espacio público y propuesta de cambio de gobierno (revolución, contrarrevolución) En tercer lugar, si observamos la dimensión electoral, Ternavasio y Galimberti han mostrado la importante “capacidad de movilización” por parte del oficialismo entre los años 1821 y 1823, a partir de los vínculos de una multiplicidad de agentes como alcaldes y jueces, policías y militares. En 1824, la lista opositora en la ciudad logra un triunfo a partir de las divisiones dentro del partido del orden, producto de conflictos anteriores como la reforma del clero. 66

2. En efecto, he tratado de mostrar que Buenos Aires no sale tan fortalecido del crítico año veinte. La contienda bélica con la República de Entre

66 TERNAVASIO, Marcela, La Revolución del voto, Política y elecciones en Buenos Aires 181o1852, Buenos Aires, Siglo XXI, 2002, pp. 116, 117, 134, 135. GALIMBERTI, Vicente, "La unanimidad...", ob. cit. 
Ríos paraliza las instituciones y afecta la vida cotidiana de un modo dramático, la movilización de sus habitantes, las dificultades para percibir sus salarios de muchos empleados, especialmente aquellos que deben empuñar las armas, resulta, claro está, caldo de cultivo para el "pasaje al acto" de posibles desórdenes políticos (era uno de los objetivos de los federales locales aliados de Ramírez) y un descrédito permanente de las autoridades gubernamentales. Es claro, además, que no hay clausura del conflicto con las provincias del litoral, ni relativa paz, pero tampoco es cierto que las fracciones opositoras locales no operen en la política provincial e interprovincial. De ahí, la circulación de redes epistolares y de relaciones personales o de alianzas informales (federales locales y del litoral).

3. Bien podría decirse, para finalizar, que los espacios de conflicto y la acción de redes interpersonales deben ser vistos en forma más abarcativa. Los cambios históricos producidos tanto en el año 1820 (incluso los de un tiempo anterior) como en el periodo de la llamada "feliz experiencia", solo pueden comprenderse en la perspectiva más amplia de ese proceso en su totalidad, en cuanto ella refleja con particular fidelidad los cambios y las continuidades maduradas en el interior de las distintas dimensiones históricas, entre otras, política, militar, interprovincial. Si los Cabildos bonaerense fueron extinguidos en una escena de indiferencia en 1821, de "tibia oposición en la Sala" y con una "pasiva actitud" por parte de los capitulares, esa política no concluye allí, sino que de algún modo el conflicto continúa como una de las propuestas disruptivas tanto en la intentona revolucionaria de agosto de 1822, como la de marzo de 1823. Si el conflicto del litoral y la invasión que de allí se hace a la provincia tienen un aparente punto de resolución con el acuerdo entre López y Rosas hacia fines de 1820, esa propuesta de invasión continúa con la guerra con la República de Entre Ríos hacia fines de 1820 y 1821 y, se mantiene de alguna manera viva, con los rumores de invasión de López durante 1822 y 1823, que llevaron a la intervención del gobierno. Si la facción opositora es vencida en la revolución de 1820, ella continúa a partir de la acción de fracciones de signos diferentes en los distintos episodios disruptivos, como la guerra con Entre Ríos, la revolución de Tagle, la contrarrevolución, etc. Si el ciclo de golpes de mano, conspiraciones del periodo de 
Pueyrredón y los ocurridos durante 1820 parecen vencidos, ellos continúan con las acciones de los Tagles, Castañeda, etc.

$-00000$

\section{Fuentes}

Archivo General de la Nación, Sala X- 32-10-1/ 32-10-2/ 13-3-6/ 4-8-3/12-5-8/

\section{Documentos éditos}

Archivo General de la Nación. Acuerdos del Extinguido Cabildo de Buenos Aires, serie IV, t IX, años 1820.1821.

Acuerdos de la Honorable Junta de Representantes 1822, Provincia de Buenos Aires, La Plata, 1981.

\section{Publicaciones periódicas}

El Ambigú de Buenos Aires

El Argos

Doña María Retazos

El Despertador

El Lobera del año 2O, o El verdadero ante-cristo

El Desengañador

Gaceta de Buenos Aires

Las Cuatro cosas

La Verdad Desnuda

La Guardia vendida por el Centinela y la traición descubierta por el oficial del día Paralipómenon al Suplemento del Teofilantrópico.

\section{Bibliografía}

AYROLO, Valentina, El abrazo reformador. Las reformas eclesiásticas en tiempos de construcción estatal Córdoba y Cuyo en el concierto iberoamericano (1813-1840), Rosario, Prohistoria, 2017.

BACZKO, Bronislaw, Los imaginarios sociales. Memorias y esperanzas colectivas, Buenos Aires, Nueva Visión, 1991.

BAGÚ, Sergio, El plan económico del grupo rivadaviano (1811-1827), Rosario, UNL, 1966.

BARRAL, María E., "Un salvavidas de plomo. Los curas rurales y la reforma eclesiástica de 1822", Prohistoria, vol. 14, Rosario, julio/diciembre, 2010.

CALVO, Nancy, "Voces en pugna, prensa política y religión en los orígenes de la República Argentina”, Hispania Sacra, vol. 61, n 122, oct., 2008, pp. 575596. 
DARNTON, Robert, Los best Sellers prohibidos en Francia antes de la revolución, México, FCE, 2008.

DI MEGLIO, Gabriel:

-iViva el bajo pueblo! La plebe urbana de Buenos Aires y la política entre la revolución de mayo y el rosismo, Buenos Aires, Prometeo, 2007.

-“La participación política popular en la provincia de Buenos Aires, 1820-1890”, en Raúl FRADKIN y G. DI MEGLIO (comp.), Hacer política. La participación para una historia popular de la revolución de independencia en el Río de la Plata, Buenos Aires, Prometeo Libros, 2013.

FORBES, John Murray, Once años en Buenos Aires (1820-1831), Buenos Aires, Emecé, 1956.

FURLONG, Guillermo, Vida y obra de Fray de Paula Castañeda: un testigo de la naciente patria argentina: 1810-1830, Buenos Aires, Editorial Castañeda, 1994.

FRADKIN, Raúl:

-“Cultura política y acción colectiva en Buenos Aires (1806-1829): un ejercicio de explicación”, en FRADKIN, Raúl, (ed.), ¿Y el pueblo dónde está? Contribuciones para una historia popular de la revolución de independencia en el Río de la Plata, Buenos Aires, Prometeo Libros, 2008.

- ¿Misión imposible? La fugaz experiencia de los jueces letrados de la primera instancia en la campaña de Buenos Aires (1822-1824)", en D. BARRIERA (comp.), Justicias y fronteras. Estudios sobre la justicia en el Río de la Plata (siglos XVII-XIX), Murcia, Editum, 2009.

FRADKIN, Raúl; GELMAN, Jorge, Juan Manuel de Rosas. La construcción de un liderazgo político, Buenos Aires, Edhasa, 2015.

GALIMBERTI, Vicente, "La unanimidad en debate. Los procesos electorales en la campaña de Buenos Aires entre 1815 y 1828”, en Boletín del Instituto de Historia Argentina y Americana “Dr. E. Ravignani”, n 37, 2012.

HALPERIN DONGHI, Tulio, Revolución y Guerra. Formación de una elite dirigente en la Argentina criolla, Buenos Aires, Siglo XXI, 1972.

HERRERO, Fabián:

-Federalistas de Buenos Aires, 1810-1820. Sobre los orígenes de la política revolucionaria, Buenos Aires, Ediciones de la UNLa, 2009.

-"Francisco Castañeda y el imaginario del orden. Sobre los inicios de la ¿feliz experiencia de Buenos Aires?”, en Valentina AYROLO (comp.), Economía, Sociedad y Política en el Río de la Plata. Problemas y debates del Siglo XIX, Rosario, Prohistoria, 2010.

-“Algunas líneas de impugnación a los 'filósofos' reformistas. Francisco Castañeda en el contexto de la reforma del clero en Buenos Aires en los inicios de 1820", Andes, n 26, Universidad Nacional de Salta, 2015. 
-“Conflictos políticos, económicos, militares...Buenos Aires y la guerra con la República de Entre Ríos”, Pasado Abierto, nº 1, Mar del Plata, enero-junio, 2015.

IRIARTE, Tomás, Memorias. Rivadavia, Monroe y la guerra argentino-brasileña, Buenos Aires, Ediciones Argentinas, 1945.

MOLINARI, Diego, iViva Ramírez!, Buenos Aires, imprenta y casa editora Coni, 1938.

MYERS, Jorge "Las paradojas de la opinión. El discurso politico rivadaviano y sus dos polos: el gobierno de las luces y la opinion pública, reina del mundo", en Hilda SABATO y Alberto LETTIERI (comp.), La vida política en la Argentina del siglo XIX. Armas, votos y voces, Buenos Aires, FCE, 2003.

PÉREZ, Mariana, "iViva España y mueran los Patricios! La conspiración de Alzaga de 1812”, en M. ALABART, M. A. FERNÁNDEZ y M. PÉREZ, Buenos Aires, una sociedad que se transforma, Buenos Aires, Prometeo, 2011.

PÉREZ, Joaquín, Historia de los primeros gobernadores de la provincia de Buenos Aires. El año XX desde el punto de vista político-social, La Plata, Archivo Histórico de la provincia de Buenos Aires, 1950.

RABINOVICH, Alejandro, "Milicias, ejércitos y guerras", en M. TERNAVASIO (Dir.), De la organización provincial a la federalización de Buenos Aires (1821-1889), Tomo 3 de la Historia de la provincia de Buenos Aires, Buenos Aires, UNIPE-Edhasa, 2013.

TERNAVASIO, Marcela:

-"Las reformas rivadavianas en Buenos Aires y el Congreso General Constituyente (1820-1827), en Noemí GOLDMAN (dir. de tomo), Nueva Historia Argentina, Buenos Aires, Sudamericana, 1998, tomo III.

-La Revolución del voto, Política y elecciones en Buenos Aires 1810-1852, Buenos Aires, Siglo XXI, 2002.

TODD, Allan, Las revoluciones, 1789-1917, Madrid, Alianza editorial, 2000.

TROISI-MELEN, Jorge, "Redes, reforma, y revolución: dos franciscanos rioplatenses sobreviviendo al siglo XIX (1800-1830), Historia Sacra, 122, julio-diciembre, 2008. 